\title{
Lysosomal acid lipase regulates VLDL synthesis and insulin sensitivity in mice
}

\author{
Branislav Radović $^{1}$ - Nemanja Vujić ${ }^{1}$ - Christina Leopold ${ }^{1}$ - Stefanie Schlager ${ }^{1}$. \\ Madeleine Goeritzer $^{1}$ - Jay V. Patankar ${ }^{1,2}$ • Melanie Korbelius ${ }^{1}$ - Dagmar Kolb ${ }^{3}$. \\ Julia Reindl $^{1}$ • Martin Wegscheider ${ }^{1}$ - Tamara Tomin ${ }^{4,5}$ • Ruth Birner-Gruenberger ${ }^{4,5}$. \\ Matthias Schittmayer $^{4,5}$. Lukas Groschner ${ }^{1,6}$ - Christoph Magnes ${ }^{7}$. \\ Clemens Diwoky ${ }^{8,9}$ - Saša Frank ${ }^{1}$ - Ernst Steyrer ${ }^{1}$ Hong Du ${ }^{10}$ - Wolfgang F. Graier ${ }^{1}$. \\ Tobias Madl ${ }^{1,5,11,12} \cdot$ Dagmar Kratky ${ }^{1}$
}

Received: 16 December 2015 / Accepted: 29 March 2016/Published online: 6 May 2016

(C) The Author(s) 2016. This article is published with open access at Springerlink.com

\begin{abstract}
Aims/hypothesis Lysosomal acid lipase (LAL) hydrolyses cholesteryl esters and triacylglycerols (TG) within lysosomes to mobilise NEFA and cholesterol. Since LAL-deficient $\left(\mathrm{Lat}^{{ }^{-}}\right)$ mice suffer from progressive loss of adipose tissue and severe accumulation of lipids in hepatic lysosomes, we hypothesised that LAL deficiency triggers alternative energy pathway(s). Methods We studied metabolic adaptations in $\mathrm{Lat}^{\gamma}$ mice. Results Despite loss of adipose tissue, $\mathrm{Lat}^{-/}$mice show enhanced glucose clearance during insulin and glucose tolerance tests and have increased uptake of $\left[{ }^{3} \mathrm{H}\right] 2$-deoxy-D-glucose into skeletal muscle compared with wild-type mice. In agreement, fasted $\mathrm{Lat}^{--}$mice exhibit reduced glucose and glycogen levels in skeletal muscle. We observed $84 \%$ decreased plasma leptin levels and significantly reduced hepatic ATP, glucose,
\end{abstract}

Electronic supplementary material The online version of this article (doi:10.1007/s00125-016-3968-6) contains peer-reviewed but unedited supplementary material, which is available to authorised users.

Dagmar Kratky

dagmar.kratky@medunigraz.at

1 Institute of Molecular Biology and Biochemistry, Center of Molecular Medicine, Medical University of Graz, Harrachgasse 21, 8010 Graz, Austria

2 Present address: Center for Molecular Medicine and Therapeutics, Department of Medical Genetics, University of British Columbia, Vancouver, BC, Canada

3 Center for Medical Research/Institute of Cell Biology, Histology and Embryology, Medical University of Graz, Graz, Austria

4 Institute of Pathology, Medical University of Graz, Graz, Austria

5 Omics Center Graz, BioTechMed-Graz, Graz, Austria glycogen and glutamine concentrations in fed $\mathrm{Lal}^{-/}$mice. Markedly reduced hepatic acyl-CoA concentrations decrease the expression of peroxisome proliferator-activated receptor $\alpha$ $\left(\right.$ PPAR $\alpha$ ) target genes. However, treatment of $\mathrm{Lal}^{-}$mice with the PPAR $\alpha$ agonist fenofibrate further decreased plasma TG (and hepatic glucose and glycogen) concentrations in $\mathrm{Lat}^{-}$ mice. Depletion of hepatic nuclear factor $4 \alpha$ and forkhead box protein a2 in fasted $\mathrm{Lal}^{-\alpha}$ mice might be responsible for reduced expression of microsomal TG transfer protein, defective VLDL synthesis and drastically reduced plasma TG levels.

Conclusions/interpretation Our findings indicate that neither activation nor inactivation of PPAR $\alpha$ per se but rather the availability of hepatic acyl-CoA concentrations regulates VLDL synthesis and subsequent metabolic adaptations in
6 Present address: Center for Neural Circuits and Behaviour, University of Oxford, Oxford, UK

7 Health, Bioanalytik und Metabolomics, Joanneum Research, Graz, Austria

8 Institute of Biomedical Engineering, Graz University of Technology, Graz, Austria

9 Present address: Institute of Molecular Biosciences, University of Graz, Graz, Austria

10

Department of Pathology and Laboratory Medicine, Indiana University School of Medicine, Indianapolis, IN, USA

11 Department of Chemistry, Technical University, Munich, Germany

12 Institute of Structural Biology, Helmholtz Zentrum, Munich, Germany 
$\mathrm{Lal}^{-}$mice. We conclude that decreased plasma VLDL production enhances glucose uptake into skeletal muscle to compensate for the lack of energy supply.

Keywords Glucose tolerance $\cdot$ Lipolysis $\cdot$ Lysosomes · VLDL

$\begin{array}{ll}\text { Abbreviations } \\ \text { BW } & \text { Body weight } \\ \text { CE } & \text { Cholesteryl ester } \\ \text { CESD } & \text { Cholesteryl ester storage disease } \\ \text { FPLC } & \text { Fast protein liquid chromatography } \\ \text { H\&E } & \text { Haematoxylin and eosin } \\ \text { ITT } & \text { Insulin tolerance test } \\ \text { LAL } & \text { Lysosomal acid lipase } \\ \text { PLIN2 } & \text { Perilipin 2 } \\ \text { PPAR } \alpha & \text { Peroxisome proliferator-activated receptor } \alpha \\ \text { scWAT } & \text { subcutaneous white adipose tissue } \\ \text { TC } & \text { Total cholesterol } \\ \text { TG } & \text { Triacylglycerol } \\ \text { TLC } & \text { Thin-layer chromatography } \\ \text { WAT } & \text { White adipose tissue } \\ \text { WD } & \text { Wolman disease } \\ \text { WT } & \text { Wild-type }\end{array}$

\section{Introduction}

Lysosomal acid lipase (LAL) hydrolyses cholesteryl esters (CE) and triacylglycerols (TG), delivered to the lysosome mainly via LDL particle uptake [1], to release mono- and diacylglycerols and mobilise cholesterol and NEFA for membrane assembly, steroidogenesis and energy production. Genetic mutations of human $L A L$ (also known as LIPA) cause an autosomal recessive lysosomal storage disorder with accumulation of $\mathrm{CE}$ predominantly in hepatocytes, adrenal glands, intestine and cells of the monocyte-macrophage system throughout the body [2]. Mutations in $L A L$ cause Wolman disease (WD) or cholesteryl ester storage disease (CESD) [3-5]. WD is a rare, neonatal-onset disease with less than $1 \%$ of LAL activity, characterised by massive hepatosplenomegaly, adrenal calcifications, malabsorption, growth retardation and cachexia. Affected patients die within the first three to 12 months of life $[2,6,7]$. CESD patients have up to $5 \%$ residual LAL activity [8], which keeps the syndrome mostly unrecognised until adulthood. These patients suffer from progressive lysosomal $\mathrm{CE}$ and TG accumulations, which lead to the characteristic liver pathology and elevated concentrations of serum transaminases, serum LDL and TG. Premature death of individuals with CESD is due to liver failure and/or accelerated atherosclerosis rather than to chronic hyperlipidaemia $[2,9,10]$.
In contrast to humans, complete loss of LAL activity in mice phenotypically resembles CESD rather than WD. LAL-deficient $\left(\mathrm{Lal}^{--}\right)$mice appear normal at birth and reach the median life span of approximately 1 year [11]. Severe accumulations of CE and TG are found predominantly in the liver, spleen, small intestine and adrenals [11-13]. $\mathrm{Lal}^{-/}$mice exhibit reduced size and body weight (BW) compared with wild-type (WT) littermates as well as progressive loss of white adipose tissue (WAT) and brown adipose tissue $[12,13]$. In this study, we explored the metabolic changes caused by impaired lysosomal TG and CE hydrolysis in $\mathrm{Lat}^{-/}$mice.

\section{Methods}

Animals Age- and sex-matched $\mathrm{Lat}^{--}$and WT littermates [13] on a $\mathrm{C} 57 \mathrm{BL} / 6 \mathrm{~J}$ background were maintained with unlimited access to chow and water in regular $12 \mathrm{~h}$ light $/ 12 \mathrm{~h}$ dark cycles. For fenofibrate treatment, 5-week-old $\mathrm{Lat}^{-/}$mice were administered $0.2 \%$ fenofibrate/chow for 4 weeks. Experimenters were blind to group assignment and outcome assessment. Animal experiments were approved by the Federal Ministry of Science, Research and Economy, Vienna, Austria. See electronic supplementary material (ESM) Methods for further details.

Lipid and hormone concentrations and fast protein liquid chromatography Cholesterol, TG, glycerol and markers of liver injury were quantified enzymatically. Lipoprotein profiles were analysed by fast protein liquid chromatography (FPLC) [14]. Hormones were determined by ELISA. See ESM Methods for further details.

ATP analysis Polar metabolites from mouse liver were extracted as described previously [15]. HPLC was performed on a 1100 Agilent capillary LC (Agilent Technologies, Santa Clara, CA, USA) equipped with a polyhydroxyethyl column (PolyLC Inc, Columbia, MD, USA). Solvent A (10 mmol/1 ammonium acetate/water $)$ and solvent $\mathrm{B}(10 \mathrm{mmol} / \mathrm{l} \mathrm{ammoni}-$ um acetate $/ 90 \%$ acetonitrile) were used in varying gradients. Selected ions/fragments were detected by TSQ Quantum Ultra Mass Spectrometry (Thermo Fisher Scientific, Waltham, MA, USA) in negative mode. See ESM Methods for further details.

De novo lipid synthesis Animals were i.p. injected with $\left[{ }^{14} \mathrm{C}\right]$ acetate $(5 \mu \mathrm{Ci}$ in $200 \mu \mathrm{l} \mathrm{PBS})$, killed $1 \mathrm{~h}$ post-injection, and livers were isolated and lyophilised for $48 \mathrm{~h}$. Lipid extracts were separated by thin-layer chromatography (TLC) (n-hexane:diethylether:acetic acid; 80:20:2, vol.:vol.:vol.). Radioactivity in bands corresponding to NEFA, TG, nonesterified cholesterol and CE was determined by liquid scintillation counting. 
Liver acyl-CoAs Acyl-CoAs were extracted from liver lysate homogenates using $0.5 \mathrm{ml}$ of buffer $\left(50 \% 0.1 \mathrm{~mol} / 1 \mathrm{KH}_{2} \mathrm{PO}_{4}\right.$, $50 \%$ 2-propanol; $\left.4^{\circ} \mathrm{C}\right), 30 \mu$ saturated $\left(\mathrm{NH}_{4}\right)_{2} \mathrm{SO}_{4}$ and $0.5 \mathrm{ml}$ acetonitrile, and centrifuged $\left(2,500 \mathrm{~g}, 10 \mathrm{~min}, 4^{\circ} \mathrm{C}\right)$. AcylCoAs were determined by liquid chromatography-mass spectrometry as described previously [16]. See ESM Methods for further details.

Neutral TG hydrolase activity Neutral TG hydrolase activity was measured as described previously [17], with minor modifications as described in ESM Methods.

Mitochondria isolation and respirometry Liver mitochondria were isolated as described previously [18] and resuspended in medium. Mitochondria were diluted in medium plus $0.2 \%$ NEFA-free BSA, $5 \mathrm{mmol} / \mathrm{l}$ glutamate, $1 \mathrm{mmol} / 1$ malate, or $5 \mathrm{mmol} / \mathrm{l}$ pyruvate, $5 \mathrm{mmol} / \mathrm{l}$ succinate, $1 \mu \mathrm{mol} / 1$ rotenone. Oxygen consumption rates were measured at $37^{\circ} \mathrm{C}$ (Oxygraph2k; Oroboros Instruments, Innsbruck, Austria). State 3respiration (mitochondrial respiration due to ADP supply) and state 4o-respiration (after ATP synthase inhibition by oligomycin) were induced by $2 \mathrm{mmol} / \mathrm{l} \mathrm{ADP}$ and $1 \mu \mathrm{g} / \mathrm{ml}$ oligomycin. Maximal uncoupled respiration was determined after titration of carbonyl cyanide $p$-trifluoromethoxyphenylhydrazone. See ESM Methods for further details.

RNA isolation and quantitative real-time PCR analysis RNA isolation and quantitative real-time PCR were performed as described previously [19]. See ESM Methods for primer sequences and further details.

VLDL secretion Mice ( 8 h-fasted) were i.p. injected with $500 \mathrm{mg} / \mathrm{kg}$ BW tyloxapol in PBS. Plasma TG were determined every hour post-injection.

Tolerance tests Mice were i.p. injected with glucose $(2 \mathrm{~g} / \mathrm{kg}$ $\mathrm{BW})$, insulin (0.25 U/kg BW), glucagon (140 $\mu \mathrm{g} / \mathrm{kg} \mathrm{BW})$, glycerol (2 $\mathrm{g} / \mathrm{kg} \mathrm{BW})$, pyruvate $(2 \mathrm{~g} / \mathrm{kg} \mathrm{BW})$ and glutamine (2 $\mathrm{g} / \mathrm{kg} \mathrm{BW}$ ). Blood glucose levels were determined using Accu-Chek Active glucometer (Roche Diagnostics, Mannheim, Germany). See ESM Methods for further details.

$\left.{ }^{3} \mathbf{H}\right] 2$-deoxy-D-glucose uptake Mice (6 h-fasted) were i.p. injected with $30 \mathrm{mg}$ glucose and $0.5 \mu \mathrm{Ci}$ glucose per $30 \mathrm{~g}$ BW. Radioactivity in $40 \mu \mathrm{l}$ plasma $(15,30$ and 60 min postinjection) and tissue lysates was determined by $\beta$-counting. See ESM Methods for further details.

Quantification of metabolites by nuclear magnetic resonance spectroscopy Liver and skeletal muscle lysates $(200 \mu \mathrm{l})$ were mixed with methanol $(400 \mu \mathrm{l})$, incubated at $-20^{\circ} \mathrm{C}(30 \mathrm{~min})$ and centrifuged. Supernatants were dried and re-dissolved in $500 \mu \mathrm{L} \mathrm{D}_{2} \mathrm{O} .{ }^{1} \mathrm{H}$-one-dimensional-nuclear magnetic resonance experiments were performed at $310 \mathrm{~K}$. Reference chemical shifts were taken from the MadisonQingdao Metabolomics Consortium Database (http://mmcd. nmrfam.wisc.edu/) [20]. Bruker Topspin3.1 (Rheinstetten, Germany) and MestReNova10.0 software (http://mestrelab. com) were used for data acquisition, processing and analyses. See ESM Methods for further details.

In vivo MRI for body fat MR images of anesthetised mice were acquired by 3T-MRI (Siemens Tim-Trio, Erlangen, Germany) with an eight-channel multipurpose coil (Noras MRI products, Hoechenberg, Germany).

Western blotting Protein samples were separated by SDSPAGE and transferred to polyvinylidene-difluoride membranes. Blots were incubated with primary antibodies followed by HRP-conjugated secondary antibodies. See ESM Methods for further details.

Subcutaneous WAT sections Tissue samples were fixed in $4 \%$ paraformaldehyde and embedded in paraffin. Tissue sections $(4 \mu \mathrm{m})$ were stained with haematoxylin and eosin $(\mathrm{H} \& \mathrm{E})$ and evaluated by light microscopy.

Electron microscopy Liver sections were fixed in phosphate buffer $/ 2.5 \%$ glutaraldehyde, washed, post-fixed in phosphate buffer/OsO $\mathrm{O}_{4}$ for $1 \mathrm{~h}$ and $4 \times 10 \mathrm{~min}$ in phosphate buffer. After dehydration, tissues were infiltrated (acetone and agar 100 epoxy resin, pure agar 100 epoxy resin) for $4 \mathrm{~h}$, placed in agar 100 epoxy resin $(8 \mathrm{~h})$, transferred into embedding moulds, and allowed to polymerise $\left(48 \mathrm{~h}, 60^{\circ} \mathrm{C}\right)$. Sections stained with lead citrate and uranyl acetate were imaged. See ESM Methods for further details.

Statistics Since $\mathrm{Lat}^{--}$mice were obviously much smaller than WT mice, in vivo experiments were not blind. In vitro experiments were blind to group assignment and outcome assessment. Statistical analyses were performed using GraphPad Prism 5.04 (GraphPad Software, San Diego, CA, USA). Significant outliers were detected by Grubb's test (http:// graphpad.com/quickcalcs/Grubbs1.cfm). Significances were determined by Student's unpaired $t$ test and Welch correction (in case of unequal variances) for two group comparison and ANOVA followed by Bonferroni correction for multiple group comparison. Data are presented as means \pm SD. Differences were considered statistically significant at $p<0.05$.

\section{Results}

Decreased acyl-CoA concentrations and peroxisome proliferator-activated receptor $\alpha$ signalling in $\mathrm{Lal}^{/-}$liver We observed severe accumulation of total cholesterol (TC) 
and TG in livers of $\mathrm{LaI}^{/-}$mice (Fig. 1a, b). Livers of WT mice store lipids within cytosolic lipid droplets, whereas in $\mathrm{Lal}^{-}$ mice lipids were entrapped within lysosomes distinguished by bilayer membranes (Fig. 1a). In addition, a substantial number of cholesterol crystals were visible. TG and CE could not be hydrolysed and remained entrapped within the lysosomes (Fig. 1b). Reduced protein expression of perilipin 2 (PLIN2) and reduced neutral TG hydrolase activity indicated a reduced number of cytoplasmic lipid droplets in $\mathrm{Lat}^{--}$livers (Fig. 1c). In accordance, acyl-CoA concentrations were reduced in livers of $\mathrm{Lal}^{-/}$mice, with markedly decreased acetyl-, palmitoleoyl-, oleoyl- and linoleoyl-CoA levels (Fig. 1d). Consistently, we observed decreased mRNA expression of fatty acid binding protein 1 (Fabpl) (Fig. 1e). Increased mRNA expression of cluster of differentiation $36(\mathrm{Cd} 36)$ but unaltered expression of LDL receptor $(L d l r)$ suggested

a
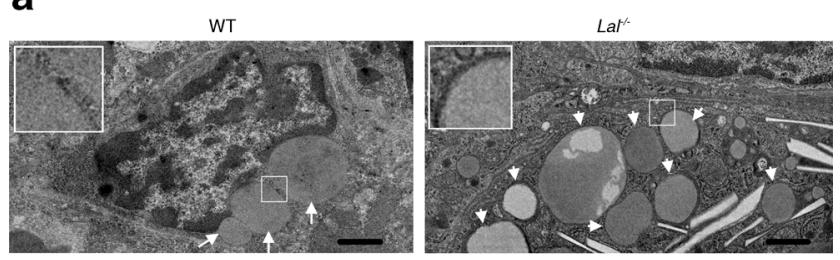

b C

d

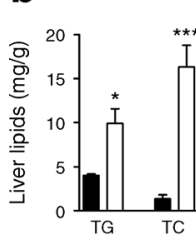

WT - $-W T-$ HT - -

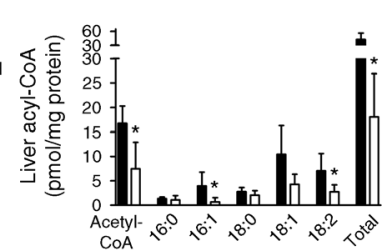

e

f
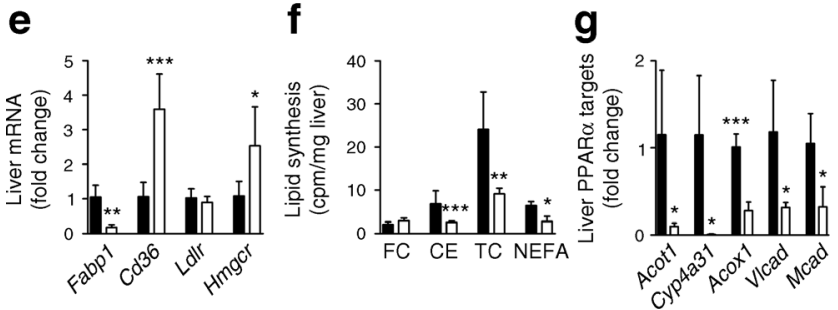

Fig. 1 Reduced concentrations of liver acyl-CoAs in $\mathrm{Lat}^{-/}$mice. (a) Electron micrographs of WT and $\mathrm{Lal}^{-/}$liver. White arrows, lipid droplets; white arrowheads, fatty lysosomes; scale bar, $1 \mu \mathrm{m}$. (b) Hepatic TG and TC concentrations $(n=3)$. (c) Hepatic expression of PLIN2 with GAPDH as loading control, and hepatic neutral TG hydrolase activity. (d) Liver acyl-CoA concentrations ( $n=4-5$ mice aged 7-9 weeks). (e) Hepatic mRNA expression of fatty acid binding protein 1 (Fabpl), cluster of differentiation $36(C d 36)$, LDL receptor $(L d l r)$ and 3-hydroxy-3-methylglutaryl-CoA reductase $(\mathrm{Hmgcr})(n=5-6)$. (f) Hepatic incorporation of i.p. injected $\left[{ }^{14} \mathrm{C}\right]$ acetate into lipid classes after TLC separation $(n=5$ mice aged 17-20 weeks); FC, non-esterified cholesterol. (g) mRNA expression of acyl-CoA thioesterase1 (Acot1), cytochrome P450, family4, subfamily a, polypeptide31 (Cyp4a31), acyl-CoA oxidase1 (Acox1), very long-chain $(\mathrm{Vlcad})$ and medium chain acyl-CoA dehydrogenase (Mcad; also known as Acadm) $(n=4-5)$. Data represent means $\pm \mathrm{SD} ; * p<0.05$, $* * p \leq 0.01, * * * p \leq 0.001$, Student's unpaired $t$ test. If not stated otherwise, mice were 12-16 weeks of age. Black bars, WT mice; white bars, Lal $^{{ }^{-}}$ mice increased NEFA and unchanged LDL uptake, respectively (Fig. 1e). Moreover, de novo cholesterol synthesis was induced in $\mathrm{Lal}^{-}$livers as indicated by increased expression of hydroxymethylglutaryl-CoA reductase (Hmgcr) (Fig. 1e) and a moderate increase in hepatic cholesterol synthesis after i.p. injection of $\left[{ }^{14} \mathrm{C}\right]$ acetate (Fig. 1f). By contrast, de novo production of TG, CE and NEFA was significantly reduced in $\mathrm{Lal}^{-\alpha}$ livers (Fig. 1f). mRNA levels of selected peroxisome proliferator-activated receptor $\alpha(\operatorname{PPAR} \alpha)$ target genes were markedly decreased in $\mathrm{Lal}^{-/}$compared with WT livers (Fig. 1g), which is in line with decreased acyl-CoA concentrations.

Intact mitochondrial function despite decreased ATP concentrations in $\mathbf{L a t ^ { - }}$ livers Since insufficient supply of NEFA and, consequently, acyl-CoA may affect mitochondrial function and energy production, we next investigated the hepatic mitochondria of $\mathrm{Lal}^{-/}$mice. Unaltered mitochondrial morphology (Fig. 2a) and a comparable amount of mitochondrial DNA (ESM Fig. 1a) indicated functional mitochondria. The respiratory capacity of mitochondria isolated from $\mathrm{Lat}^{-/}$livers was decreased only for the uncoupled state when succinate

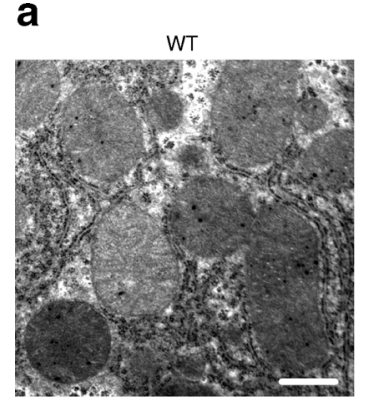

b

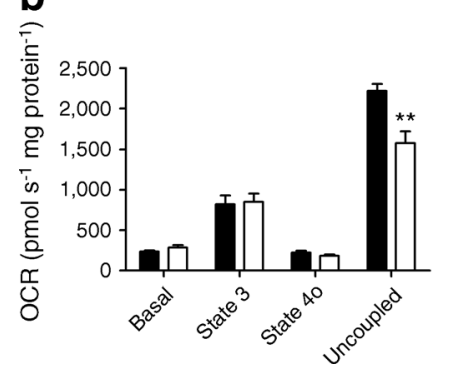

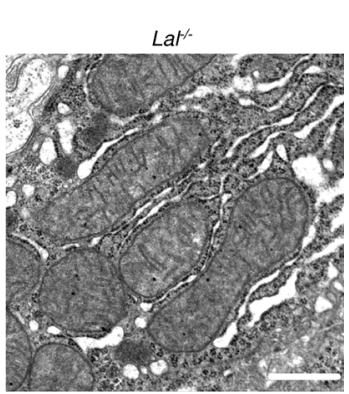

$\mathbf{C}$

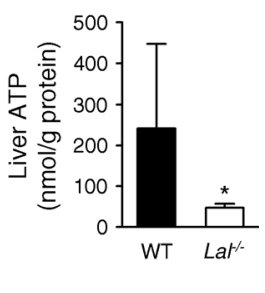

Fig. 2 Intact mitochondria and reduced ATP concentrations in $\mathrm{Lat}^{-/}$ livers. (a) Electron micrographs of mitochondria in livers of WT and $\mathrm{Lat}^{-/}$mice aged 12 weeks; scale bar, $0.5 \mu \mathrm{m}$. (b) Mitochondrial respiration of mitochondria isolated from WT and $\mathrm{Lat}^{-}$livers $(n=4-6)$ using $10 \mathrm{mmol} / 1$ succinate $/ 1 \mu \mathrm{mol} / \mathrm{l}$ rotenone as substrates. Oxygen consumption rate presented as basal mitochondrial respiration in the presence of substrates (basal), increased mitochondrial respiration due to ADP supply (state 3), after ATP synthase inhibition by oligomycin (state 4o) and after carbonyl cyanide $p$-trifluoromethoxyphenylhydrazone addition (uncoupled). (c) Liver ATP concentrations determined by liquid chromatography-tandem mass spectrometry ( $n=5-6$ mice aged 8-12 weeks). Data represent means $\pm \mathrm{SD} ;{ }^{*} p<0.05,{ }^{* *} p \leq 0.01$, Student's unpaired $t$ test. Black bars, WT mice; white bars, $\mathrm{Lal}^{-/}$mice. OCR, oxygen consumption rate 
was provided as substrate (Fig. 2b) but unaltered with glutamate in the presence of malate (ESM Fig. 1b) or pyruvate (ESM Fig. 1c). These data suggest that the lack of substrate (acyl-CoA) might be responsible for reduced ATP concentrations in $\mathrm{Lat}^{-\alpha}$ livers (Fig. 2c).

Diminished VLDL secretion in $\mathrm{Lal}^{-\alpha}$ mice Since $\mathrm{Lat}^{-/}$mice suffer from progressive loss of adipose tissue, we expected lipid metabolism during fasting to be severely affected. Interestingly, fasting failed to increase circulating TG concentrations in $\mathrm{Lal}^{-/}$mice (Fig. 3a), whereas TC was increased in $\mathrm{Lal}^{-/}$mice regardless of the feeding state. Plasma lipoprotein profiles of fasted $\mathrm{Lat}^{-/}$mice revealed increased levels of LDLcholesterol and decreased levels of HDL-cholesterol (Fig. 3b). However, in contrast to WT mice, Lal $^{-/}$mice failed to induce VLDL-TG during fasting, with redistribution of TG toward the LDL fraction (Fig. 3c). Biochemical estimation confirmed the FPLC data, showing no difference after $4 \mathrm{~h}$ and reduced plasma TG concentrations after $12 \mathrm{~h}$ of fasting (Fig. $3 \mathrm{~d}$ ).

We next investigated VLDL secretion after inhibition of peripheral lipolysis by tyloxapol and found strongly reduced
VLDL release in fasted $\mathrm{Lal}^{\gamma_{-}^{-}}$mice (Fig. 3e). As expected, $\mathrm{Lal}^{/-}$ mice showed markedly increased concentrations of aminotransferases (ESM Fig. 2), an indication of liver damage. Hepatic mRNA expression of microsomal TG transfer protein (Mttp), a key player in VLDL assembly, was decreased (Fig. 3f). Drastically reduced mRNA and protein expression of the hepatic transcription factors hepatocyte nuclear factor 4a (Hnf4a) and forkhead box protein a2 (Foxa2) (Fig. 3f, g), which are involved in VLDL synthesis [21, 22], reflect a causal link between low expression levels of these transcription factors and decreased VLDL secretion in $\mathrm{Lal}^{-/}$livers.

Increased insulin sensitivity in $\boldsymbol{L a t}^{/-}$mice Severe impairment of lipid metabolism in $\mathrm{Lal}^{-/}$mice and reduced acylCoA and TG availability prompted us to investigate metabolic adaptations to defective lipid metabolism. Intraperitoneal glucose tolerance tests and insulin tolerance tests (ITT) revealed significantly improved glucose tolerance (Fig. 4a) and insulin sensitivity (Fig. 4b) in $\mathrm{Lal}^{-/}$mice. Plasma glucose levels were reduced (Fig. 4c), whereas insulin levels were comparable between $\mathrm{Lal}^{-\alpha}$ and WT mice (Fig. 4d). These data indicate

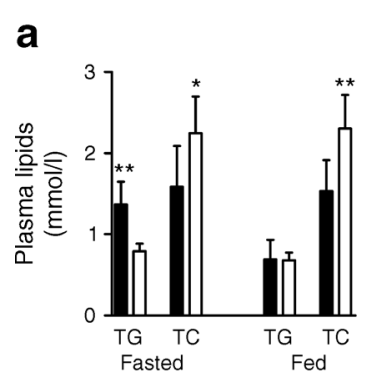

d

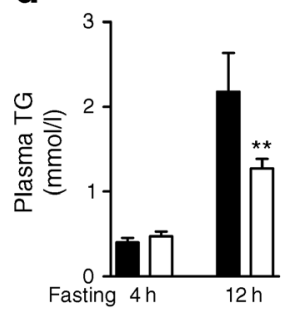

e

b
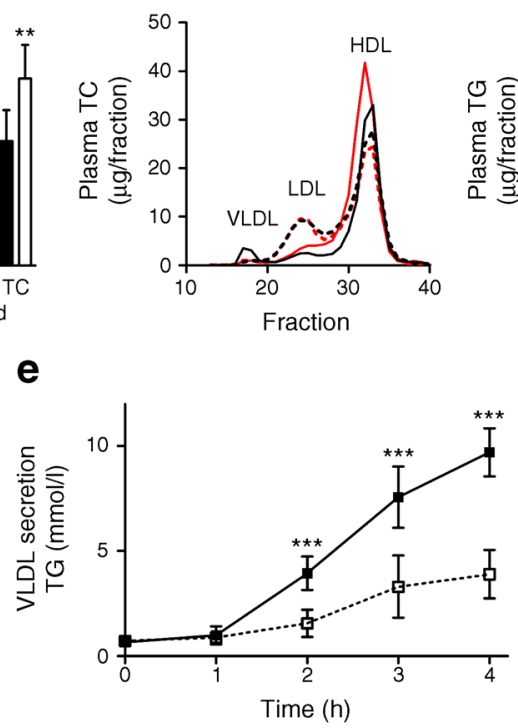

C

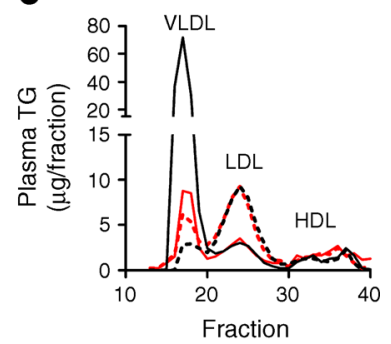

f

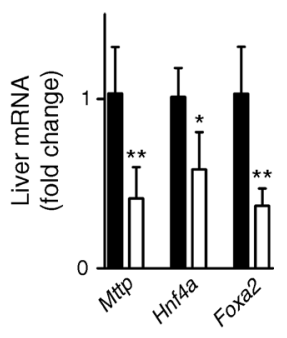

$\mathbf{g}$

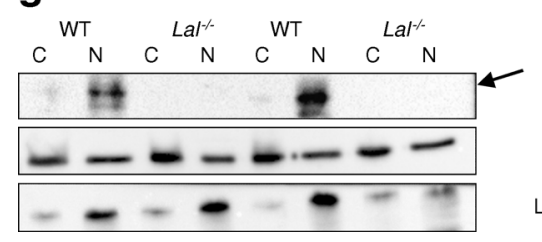

Fig. 3 Abolished nuclear expression of HNF4 $\alpha$ and FOXA2 and decreased VLDL synthesis in $\mathrm{Lal}^{--}$mice. (a) Plasma TG and TC concentrations in $12 \mathrm{~h}$ fasted $(n=5)$ and fed mice $(n=7-9)$. Distribution of (b) TC and (c) TG within plasma lipoproteins $(n=6)$; continuous lines, WT; dotted lines, $\mathrm{Lal}^{-}$; red lines, $4 \mathrm{~h}$ fasting; black lines, $12 \mathrm{~h}$ fasting. (d) Plasma TG concentrations of $4 \mathrm{~h}$ and $12 \mathrm{~h}$ fasted mice $(n=5)$. (e) VLDL secretion of $8 \mathrm{~h}$ fasted mice $(n=4-7)$ after tyloxapol injection. (f) Hepatic mRNA expression of microsomal TG transfer protein (Mttp), hepatic

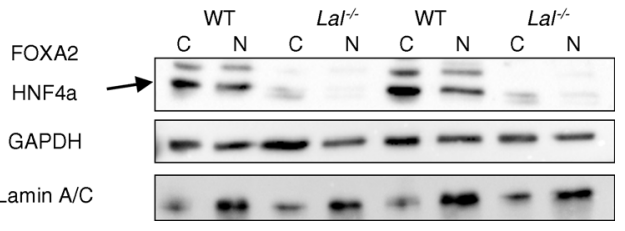

nuclear factor $4 \alpha$ (Hnf4a) and forkhead box protein a2 (Foxa2) $(n=5$ 6). (g) Immunoblotting against liver HNF4a and FOXA2 (both in fasted state) in cytosolic (C) and nuclear (N) fractions with GAPDH and LaminA/C as loading controls. Data represent means $\pm \mathrm{SD} ;{ }^{*} p<0.05$, $* * p \leq 0.01, * * * p \leq 0.001$. (a, d, f) Student's unpaired $t$ test, (e) ANOVA. Mice were aged 12-16 weeks. Black bars and squares, WT mice; white bars and squares, $\mathrm{Lat}^{-}$mice 

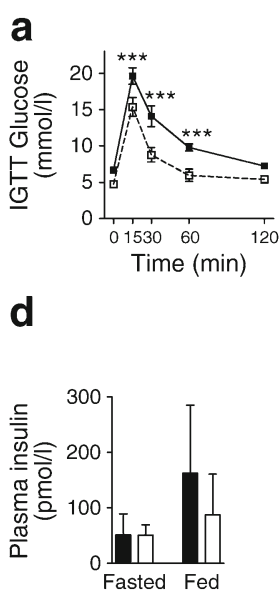

b
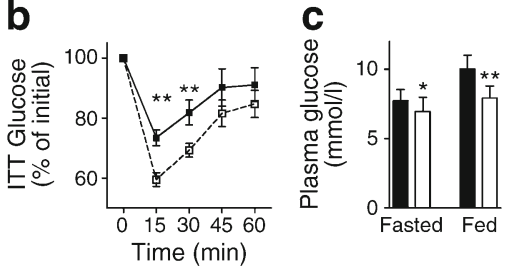

e
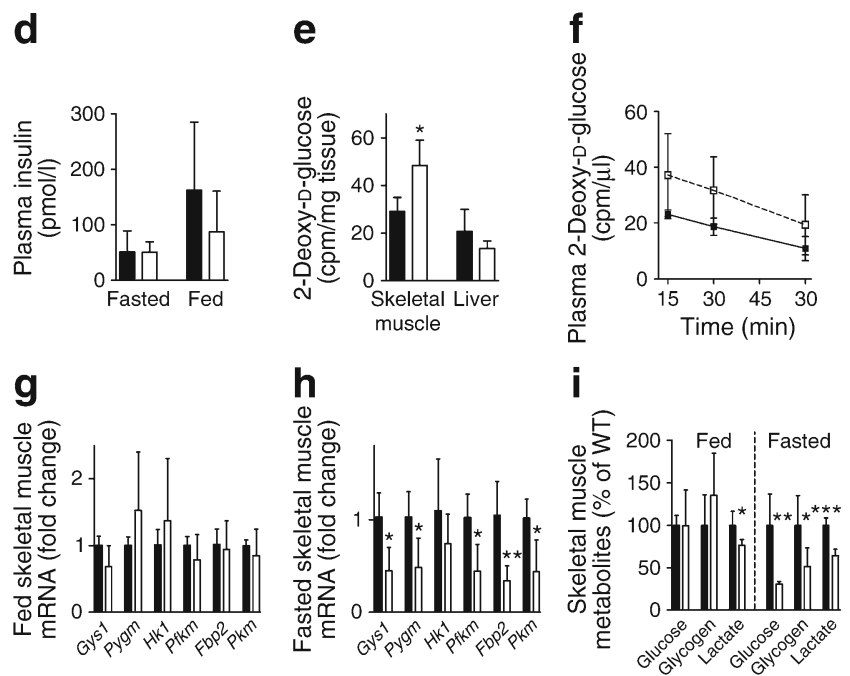

Fig. 4 Improved glucose tolerance and insulin sensitivity in $\mathrm{Lat}^{--}$mice. Plasma glucose concentrations in (a) $6 \mathrm{~h}$ fasted and (b) $4 \mathrm{~h}$ fasted mice $(n=5)$ after i.p. injection of (a) glucose $(2 \mathrm{~g} / \mathrm{kg})$ and (b) insulin $(0.25$ $\mathrm{U} / \mathrm{kg})$. Concentrations of (c) plasma glucose in $6 \mathrm{~h}$ fasted $(n=14)$ and fed $(n=7)$ mice and (d) insulin in $4 \mathrm{~h}$ fasted and fed mice $(n=4)$. (e) Radioactivity in skeletal muscle, liver and (f) plasma of mice $(n=5)$ after i.p. injection of $\left[{ }^{3} \mathrm{H}\right] 2$-deoxy-D-glucose. mRNA expression of glycogen synthase1 (Gys 1), glycogen phosphorylase (Pygm), hexokinase 1 (Hkl), phosphofructokinase (Pfkm), fructose-biphosphatase2 (Fbp2) and pyruvate kinase $(P \mathrm{~km})$ in skeletal muscles of $(\mathbf{g})$ fed and $(\mathbf{h}) 12 \mathrm{~h}$ fasted mice $(n=4-5)$. (i) Skeletal muscle metabolites of fed and $12 \mathrm{~h}$ fasted mice $(n=5)$. Data represent means $\pm \mathrm{SD} ; * p<0.05, * * p \leq 0.01$, $* * * p \leq 0.001$. $(\mathbf{a}, \mathbf{b}, \mathbf{f})$ ANOVA, $(\mathbf{c}-\mathbf{e}, \mathbf{g}-\mathbf{i})$ Student's unpaired $t$ test. Mice were aged $12-16$ weeks. Black bars and squares, WT mice; white bars and squares, $\mathrm{Lat}^{-/}$mice

increased usage of glucose in $\mathrm{Lat}^{-}$mice. Accordingly, the uptake of i.p. injected $\left[{ }^{3} \mathrm{H}\right] 2$-deoxy-D-glucose into skeletal muscles was increased by 1.9 -fold in $\mathrm{Lat}^{-}$mice (Fig. 4e). $\left.{ }^{3} \mathrm{H}\right] 2$-deoxyD-glucose uptake by $L a l^{-}$livers (Fig. $4 \mathrm{e}$ ) as well as radioactivity in plasma (Fig. 4f) were comparable between both genotypes. mRNA expression of glycolysis genes in skeletal muscles were comparable in fed (Fig. 4g) and reduced in fasted $\mathrm{Lat}^{--}$mice (Fig. 4h). In agreement, glucose and glycogen concentrations were decreased in fasted $\mathrm{Lal}^{-}$mice (Fig. 4i), whereas muscle lactate was reduced in both fed and fasted states.

Decreased plasma leptin concentrations and altered expression of hepatic adiponectin and leptin receptors in $\boldsymbol{L a} \boldsymbol{I}^{-}$mice Despite comparable food intake, $\mathrm{Lal}^{-\alpha}$ mice were lighter and gained less weight (ESM Fig. 3a, b). They lacked visceral fat and exhibited markedly reduced subcutaneous (sc)
WAT at the age of 4 and 12 weeks (ESM Fig. 3c). H\&E staining of scWAT sections revealed smaller adipocytes with reduced fat content (Fig. 5a) and we observed reduced inguinal scWAT mass (Fig. 5b) in $\mathrm{Lal}^{-\alpha}$ mice. Adipose tissue fundamentally influences systemic insulin sensitivity and glucose metabolism via the adipokines leptin and adiponectin [23]. Leptin mRNA expression was significantly decreased in scWAT of $\mathrm{Lal}^{-/-}$compared with WT mice, whereas adiponectin mRNA expression was unchanged (Fig. 5c). Since fasting significantly decreases basal leptin levels [24], decreased plasma leptin concentrations (84\%) in fed $\mathrm{Lal}^{-}$ mice but comparable levels as WT mice after fasting (Fig. 5d) indicate that feeding is ineffective to increase the satiety hormone leptin in $\mathrm{Lal}^{-/}$mice. Plasma adiponectin levels were comparable between both genotypes (Fig. 5e). mRNA expression of the leptin receptors (Leptr) 1 and 2 were markedly increased in livers of fed (Fig. 5f) and fasted (Fig. $5 \mathrm{~g}$ ) $\mathrm{Lal}^{--}$mice. Expression of adiponectin receptor (Adipor) 1 mRNA was higher and expression of Adipor 2 mRNA was lower in livers of fed $\mathrm{Lal}^{--}$mice than WT fed mice (Fig. 5f). While Adiporl mRNA levels were similar in fasted livers of both genotypes, transcript levels of Adipor 2

\section{a}
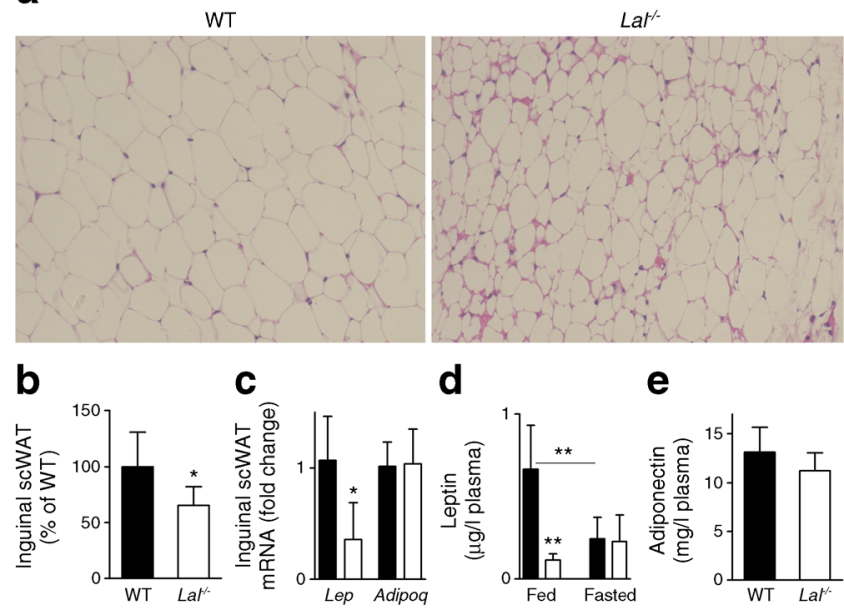

f

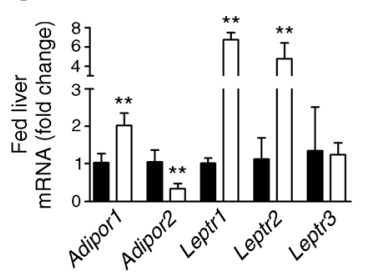

$\mathbf{g}$

Fig. 5 Reduced scWAT and plasma leptin concentrations in $\mathrm{Lat}^{-/}$mice. (a) H\&E staining of inguinal scWAT sections. (b) scWAT mass normalised to BW $(n=6)$. (c) mRNA expression of leptin (Lep) and adiponectin (Adipoq) in scWAT $(n=4-5)$. Plasma concentrations of (d) leptin and (e) adiponectin $(n=6)$. mRNA expression of the receptors of hepatic leptin (Leptr) and adiponectin (Adipor) in (f) fed and (g) $12 \mathrm{~h}$ fasted WT and $\mathrm{Lat}^{-}$mice $(n=3-5)$. Data represent means $\pm \mathrm{SD} ;{ }^{*} p<0.05,{ }^{*} p \leq 0.01$; ${ }^{* * *} p \leq 0.001$, Student's unpaired $t$ test. Mice were aged 12-16 weeks. Black bars, WT mice; white bars, $\mathrm{Lat}^{-/}$mice 
were reduced in livers of $\mathrm{Lal}^{{ }^{-}}$mice compared with WT livers (Fig. 5g).

Reduced liver glucose, glycogen and glutamine concentrations in $\mathbf{L a t}^{/-}$mice Significantly reduced plasma glycerol concentrations in fasted $\mathrm{Lal}^{-/}$mice indicate diminished peripheral lipolysis (Fig. 6a). Reduced liver glycogen concentrations in fed $\mathrm{Lal}^{-/}$mice (Fig. 6b) were confirmed by decreased mobilisation of glucose from glycogen after i.p. injection of glucagon (Fig. 6c). Reduced liver storage of glucose is a result of ineffective production or extensive usage. We therefore determined the ability of $\mathrm{Lat}^{-/}$mice to produce glucose from different carbon sources. After i.p. injection of glycerol, de novo synthesised glucose reached similar maximal values after $30 \mathrm{~min}$ in WT and after $15 \mathrm{~min}$ in $\mathrm{Lat}^{-/}$mice (Fig. 6d). Thus, glucose was cleared faster from the circulation in $\mathrm{Lal}^{-/}$ mice as shown by significantly decreased levels after $60 \mathrm{~min}$, implying increased systemic glucose usage. Gluconeogenesis
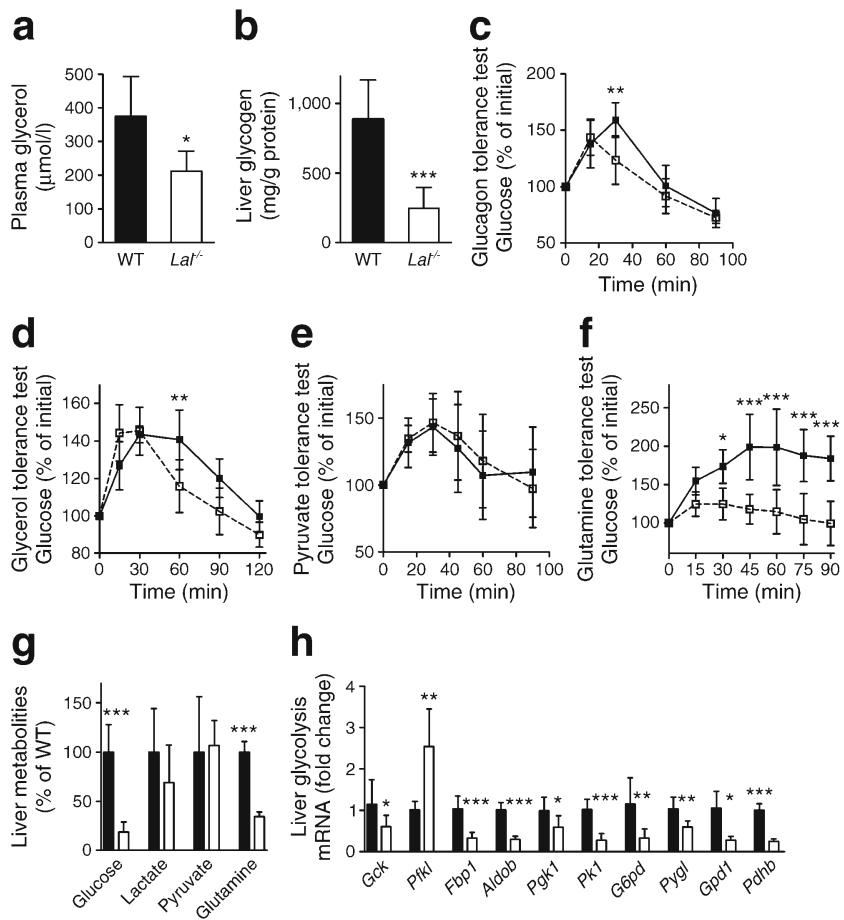

h

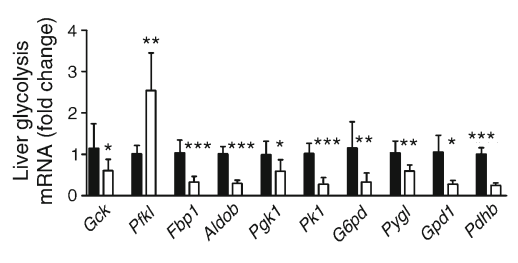

Fig. 6 Reduced glycogen, glucose and glutamine concentrations in $\mathrm{Lat}^{-}$ livers. (a) Plasma glycerol in fasted $(n=5)$ and (b) liver glycogen concentrations in fed mice $(n=8)$. (c-f) Glucose concentrations after i.p. injection of (c) glucagon (140 $\mu \mathrm{g} / \mathrm{kg} \mathrm{BW})$, (d) glycerol (2 g/kg BW), (e) pyruvate $(2 \mathrm{~g} / \mathrm{kg} \mathrm{BW})$ and (f) glutamine $(2 \mathrm{~g} / \mathrm{kg} \mathrm{BW})$ in plasma of (c) fed and (d-f) fasted mice $(n=5-7)$. (g) Liver metabolites in fed mice $(n=6)$. (h) mRNA expression of glucokinase $(G c k)$, phosphofructokinase $(P f k l)$, fructose-biphosphatase $1(F b p l)$, aldolase B (Aldob), phosphoglycerate kinase $1(P g k 1)$, pyruvate kinase $1(P k 1)$, glucose-6-phosphate dehydrogenase ( $G 6 p d$; also known as $G 6 p d x)$, glycogen phosphorylase $(P y g l)$, glycerol-3-phosphate dehydrogenase1 (Gpdl) and pyruvate dehydrogenase $(P d h b)(n=6-9)$. Data represent means $\pm \mathrm{SD} ; * p<0.05$, $* * p \leq 0.01, * * * p \leq 0.001$. (a, b, g, h) Student's unpaired $t$ test, $(\mathbf{c}-\mathbf{f})$ ANOVA. Mice were aged 12-18 weeks. Black bars and squares, WT mice; white bars and squares, $\mathrm{Lal}^{-/}$mice as measured by pyruvate tolerance test was unaltered (Fig. 6e), but drastically decreased in $\mathrm{Lal}^{-/}$mice after i.p. injection of glutamine (Fig. 6f). In line, hepatic glucose and glutamine concentrations were markedly reduced in livers of fed $\mathrm{Lat}^{/-}$mice (Fig. 6g), whereas lactate and pyruvate levels were comparable to those in WT mice. Decreased hepatic glucose content may be a reason why (with the exception of liver-specific phosphofructokinase $[P f k l])$ the mRNA expression levels of all other liver enzymes involved in glycolysis were reduced in $\mathrm{Lat}^{-/}$livers (Fig. 6h).

PPAR $\alpha$ activation reduces liver glucose and glycogen as well as plasma TG concentrations in $\mathbf{L a t}{ }^{--}$mice To investigate whether alterations in glucose homeostasis and VLDL synthesis in $\mathrm{LaI}^{-}$mice are mediated by diminished PPAR $\alpha$ activation, $\mathrm{Lal}^{-}$mice were fed fenofibrate for 4 weeks. We observed decreased hepatic glucose and completely depleted glycogen content in fenofibrate-treated $\mathrm{Lat}^{-/}$mice (Fig. 7a). Lactate concentrations in the liver were unaffected, whereas plasma lactate levels were reduced (Fig. 7b). Moreover, fenofibrate treatment reduced liver TC and plasma TG concentrations (Fig. 7c, d). We further found induced expression of the PPAR $\alpha$ targets Cyp4a31 and Vlcad (also known as Acadvl), reduced Adiporl transcript level and increased expression of Leptrl (Fig. 7e). Importantly, relative mRNA expression levels of Mttp, Hnf $4 a$ and Foxa 2 remained comparable between untreated and fenofibrate-treated $\mathrm{Lat}^{-/}$mice. We conclude that defective VLDL synthesis in $\mathrm{Lat}^{-}$mice is a

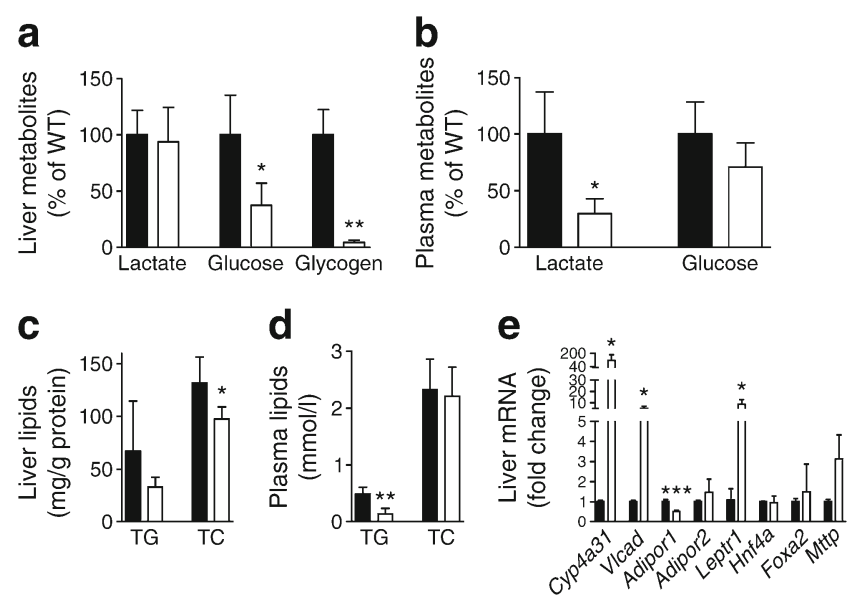

Fig. 7 Reduced plasma TG and liver glucose and glycogen in fenofibrate-treated $\mathrm{Lat}^{\prime-}$ mice. Five-week-old $\mathrm{Lat}^{\prime-}$ mice were administered fenofibrate $(0.2 \%)$ for 4 weeks. (a) Hepatic lactate, glucose and glycogen, and (b) plasma lactate and glucose concentrations $(n=5)$. TG and TC concentrations in (c) liver and (d) plasma $(n=4)$. (e) mRNA expression of cytochrome P450, family4, subfamily a, polypeptide 31 (Cyp4a31), very long-chain chain acyl-CoA dehydrogenase (Vlcad), adiponectin receptors (Adiporl and 2), leptin receptor 1 (Leptr 1), hepatic nuclear factor $4 \alpha(H n f 4 a)$, forkhead box protein a2 (Foxa2) and microsomal TG transfer protein (Mttp) $(n=3-4)$. Data represent means \pm SD; $* p<0.05, * * p \leq 0.01, * * * p \leq 0.001$. Student's unpaired $t$ test. Black bars, $\mathrm{Lal}^{--}$mice; white bars, fenofibrate-treated $\mathrm{Lal}^{-/}$mice 
consequence of diminished hepatic HNF $4 \alpha /$ FOXA2 signalling rather than PPAR $\alpha$ inactivation.

\section{Discussion}

The appearance of hepatic 'fatty lysosomes' in insulin-sensitive $\mathrm{Lat}^{-}$mice contrasts with hepatosteatosis, in which accumulation of cytoplasmic lipid droplets is accompanied by insulin resistance [25-27]. Liver is the main organ for VLDL assembly and secretion and thus influences whole body TG and cholesterol homeostasis [28]. Skop et al have already suggested the involvement of LAL in VLDL synthesis [29]. The authors linked the process to autophagy, since inhibition of lysosomal activity by chloroquine decreased VLDL secretion in vitro. Our in vivo data, however, indicate that defective VLDL synthesis in $\mathrm{Lat}^{-\mathrm{-}}$ mice is a consequence of decreased hepatic availability of acylCoAs, which then leads to downregulation of PPAR $\alpha$ signalling, nuclear exclusion of HNF $\alpha$ and FOXA2, decreased Mttp expression, reduced TG synthesis, and eventually futile lipidation of ApoB [21, 22, 30, 31]. In general, PPAR $\alpha$ activation mediates lipid oxidation and reduces ectopic lipid storage, thereby counteracting insulin resistance [32]. Interestingly, $\mathrm{Lat}^{-\alpha}$ mice show reduced expression of PPAR $\alpha$ target genes, yet produce less VLDL, which contrasts with the increased secretion of VLDL observed in Ppara $^{-/}$mice [33]. However, fenofibrate treatment did not normalise the phenotype but further decreased plasma TG (and hepatic glucose and glycogen) concentrations in $\mathrm{Lat}^{-}$mice. These findings indicate that neither activation nor inactivation of PPAR $\alpha$ per se but rather the availability of hepatic acyl-CoAs regulates VLDL synthesis and subsequent metabolic adaptations.

$\mathrm{HNF} 4 \alpha$, a key regulator of various metabolic pathways, is classified as an orphan receptor despite NEFA being suggested as its endogenous ligand [34]. In fact, Yuan et al demonstrated that $\mathrm{HNF} 4 \alpha$ is selectively associated with linoleic acid in mammalian cells and in the liver of fed mice [35], indicating that linoleic acid is at least one possible endogenous ligand for HNF4 $\alpha$. Nuclear exclusion of $\mathrm{HNF} 4 \alpha$ together with a $60 \%$ reduction in 18:2-CoA in livers of $\mathrm{Lal}^{--}$mice suggest that lysosomal mobilisation of linoleic acid is involved in VLDL synthesis via the HNF $4 \alpha$ pathway. Accordingly, protein expression of FOXA2, which is controlled by insulin signalling [36] and promotes VLDL synthesis [21], was significantly reduced in $\mathrm{Lat}^{--}$liver. Besides reduced VLDL secretion, $\mathrm{Lat}^{-/}$mice had increased insulin sensitivity compared with their WT littermates. This finding is in accordance with studies in animal models [37, 38] and type 2 diabetes patients [39], indicating a connection between insulin resistance and VLDL overproduction. We thus propose that reduced plasma VLDL is one of the features to induce a shift from NEFA to glucose utilisation, resulting in improved insulin sensitivity as observed by enhanced uptake of glucose in skeletal muscles of these mice. Although non-significant, a $35 \%$ increase of skeletal muscle glycogen in fed $\mathrm{Lat}^{-\alpha}$ mice indicates enhanced storage of glucose for energy supply during fasting.

WAT is a primary contributor to metabolic regulation during feeding and fasting. Although lipodystrophy is generally associated with insulin resistance [40], $\mathrm{Lat}^{--}$mice show reduced plasma glucose and enhanced glucose usage. Despite substantial loss of WAT mass in $\mathrm{Lat}^{-}$mice, plasma concentrations of adiponectin were comparable, whereas leptin levels were profoundly decreased after feeding. These findings indicate that $\mathrm{Lat}^{-}$mice have a constant energy demand due to the unavailability of NEFA from WAT cytosolic lipid droplets. Diminished VLDL synthesis induces depletion of liver energy storage pools as reflected by reduced liver glycogen, glucose and glutamine concentrations. Decreased liver glucose levels may be causative for lower hepatic mRNA expression of genes involved in glycolysis, particularly of Gck and $P k 1$ (also known as $P k l r)$. The liver provides glucose through gluconeogenesis from non-carbohydrate precursors during prolonged fasting [41]. $\mathrm{Lal}^{-}$mice, however, are unable to produce glucose from external glutamine, suggesting that the degradation of glutamine to pyruvate is defective. However, gluconeogenesis

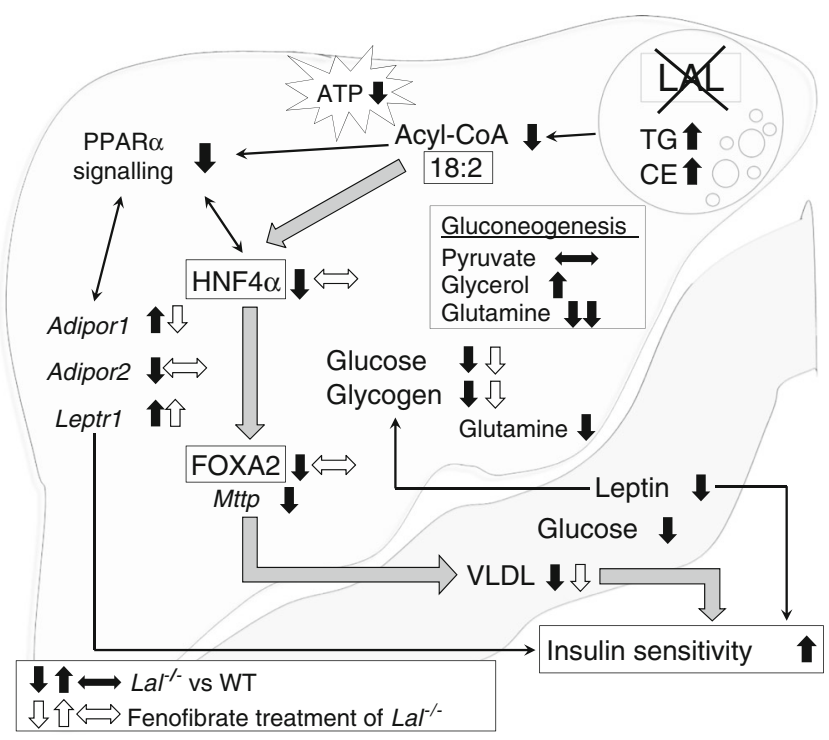

Fig. 8 Decreased hepatic acyl-CoA availability reduces VLDL synthesis and triggers insulin sensitivity in $\mathrm{Lat}^{-}$mice. Inhibited hepatic lysosomal hydrolysis of CE and TG due to LAL deficiency leads to reduced abundance of cellular acyl-CoA and ATP. Consequently, decreased expression of the PPAR $\alpha$ targets, HNF4 $\alpha$, FOXA2 and Mttp results in defective hepatic VLDL secretion. Decreased plasma glucose and leptin, and reduced liver glucose, glycogen and glutamine concentrations in fed $\mathrm{Lat}^{-}$ mice indicate increased energy demand and extensive systemic usage of glucose. Treatment with the PPAR $\alpha$ agonist fenofibrate further reduces plasma TG, liver glucose and glycogen concentrations in $\mathrm{Lat}^{-/}$mice, indicating that VLDL synthesis and insulin sensitivity is PPAR $\alpha$-independent. Decreased VLDL production might be a consequence of reduced hepatic acyl-CoA concentrations, particularly the HNF4a ligand linoleic acid (18:2). Glucose tolerance and insulin sensitivity are increased to compensate for decreased energy availability 
per se is functional, as shown by unaltered pyruvate tolerance tests. Glycerol tolerance test revealed earlier maximal glucose levels and glucose was cleared faster from the circulation, confirming enhanced glucose utilisation in $\mathrm{Lal}^{-\alpha}$ mice.

We conclude that defective lysosomal hydrolysis of $\mathrm{CE}$ and TG decreases hepatic acyl-CoA and ATP concentrations. Consequently, abolished nuclear expression of $\mathrm{HNF} 4 \alpha$ and FOXA2 lead to reduced Mttp expression and attenuated VLDL secretion, which in turn induces insulin sensitivity (Fig. 8). During the past 30-40 years, our understanding of proteins and lipids that influence VLDL assembly and secretion has changed tremendously [42]. We argue that LAL should be included as another critical player, which regulates VLDL and glucose metabolism.

Acknowledgements Open access funding provided by Medical University of Graz. The authors thank S. Rainer and A. Ibovnik (Medical University of Graz, Austria) for excellent technical assistance, R. Schreiber (University of Graz, Austria) for providing the PLIN2 antibody, E. Bernhart for providing the Lamin A/C antibody (Medical University of Graz, Austria) and I. Hindler (Medical University of Graz, Austria) for the care of the mice.

Funding This work was supported by the Austrian Science Fund FWF (DK-MCD W1226, P27070, P22832, SFB-LIPOTOX F3004) (DKr), the $\mathrm{PhD}$ programme 'Molecular Medicine' of the Medical University of Graz and BioTechMed-Graz. TM was supported by the Bavarian Ministry of Sciences, Research and the Arts (BioSysNet), the German Research Foundation (MA 5703/1-1), the Centre for Integrated Protein Science, Munich, the President's International Fellowship Initiative of CAS (No: 2015VBB045) and the National Natural Science Foundation of China (No. 31450110423).

Duality of interest The authors declare that there is no duality of interest associated with this manuscript.

Contribution statement $\mathrm{BR}$ and $\mathrm{DK}$ conceived and designed the study and wrote the paper. BR, NV, CL, SS, MG, JVP, MK, DKo, JR, MW, TT, MS, LG, CM, CD and TM contributed to data collection and analyses. RBG, SF, ES, HD, WFG and TM contributed to study design and data interpretation. All authors critically revised the manuscript and have read and approved the final version. DK is responsible for the integrity of the work as a whole.

Open Access This article is distributed under the terms of the Creative Commons Attribution 4.0 International License (http:// creativecommons.org/licenses/by/4.0/), which permits unrestricted use, distribution, and reproduction in any medium, provided you give appropriate credit to the original author(s) and the source, provide a link to the Creative Commons license, and indicate if changes were made.

\section{References}

1. Brown MS, Goldstein JL (1976) Receptor-mediated control of cholesterol metabolism. Science 191:150-154
2. Assmann G, Seedorf U (1995) Acid lipase deficiency: Wolman disease and cholesteryl ester storage disease. In: Scriver CR, Beaudet AL, Sly WS, Valle D (eds) The metabolic and molecular basis of inherited disease, 7th edn. McGraw and Hill, New York, pp 2563-2587

3. Burke JA, Schubert WK (1972) Deficient activity of hepatic acid lipase in cholesterol ester storage disease. Science 176:309-310

4. Patrick AD, Lake BD (1969) Deficiency of an acid lipase in Wolman's disease. Nature 222:1067-1068

5. Sloan HR, Fredrickson DS (1972) Enzyme deficiency in cholesteryl ester storage disease. J Clin Invest 51:1923-1926

6. Wolman M, Sterk VV, Gatt S, Frenkel M (1961) Primary familial xanthomatosis with involvement and calcification of the adrenals. Report of two more cases in siblings of a previously described infant. Pediatrics 28:742-757

7. Marshall WC, Ockenden BG, Fosbrooke AS, Cumings JN (1969) Wolman's disease. A rare lipidosis with adrenal calcification. Arch Dis Child 44:331-341

8. Brown MS, Sobhani MK, Brunschede GY, Goldstein JL (1976) Restoration of a regulatory response to low density lipoprotein in acid lipase-deficient human fibroblasts. J Biol Chem 251:32773286

9. Seedorf U, Wiebusch H, Muntoni S et al (1995) A novel variant of lysosomal acid lipase (Leu336->Pro) associated with acid lipase deficiency and cholesterol ester storage disease. Arterioscler Thromb Vasc Biol 15:773-778

10. Pisciotta L, Fresa R, Bellocchio A et al (2009) Cholesteryl Ester Storage Disease (CESD) due to novel mutations in the LIPA gene. Mol Genet Metab 97:143-148

11. Aqul A, Lopez AM, Posey KS et al (2014) Hepatic entrapment of esterified cholesterol drives continual expansion of whole body sterol pool in lysosomal acid lipase-deficient mice. Am J Physiol Gastrointest Liver Physiol 307:G836-847

12. Du H, Duanmu M, Witte D, Grabowski GA (1998) Targeted disruption of the mouse lysosomal acid lipase gene: long-term survival with massive cholesteryl ester and triglyceride storage. Hum Mol Genet 7:1347-1354

13. Du H, Heur M, Duanmu M et al (2001) Lysosomal acid lipasedeficient mice: depletion of white and brown fat, severe hepatosplenomegaly, and shortened life span. J Lipid Res 42:489-500

14. Chandak PG, Obrowsky S, Radovic B et al (2011) Lack of acylCoA:diacylglycerol acyltransferase 1 reduces intestinal cholesterol absorption and attenuates atherosclerosis in apolipoprotein $\mathrm{E}$ knockout mice. Biochim Biophys Acta 1811:1011-1020

15. Yuan M, Breitkopf SB, Yang X, Asara JM (2012) A positive/ negative ion-switching, targeted mass spectrometry-based metabolomics platform for bodily fluids, cells, and fresh and fixed tissue. Nat Protoc 7:872-881

16. Magnes C, Suppan M, Pieber TR et al (2008) Validated comprehensive analytical method for quantification of coenzyme A activated compounds in biological tissues by online solid-phase extraction LC/MS/MS. Anal Chem 80:5736-5742

17. Schweiger M, Eichmann TO, Taschler U, Zimmermann R, Zechner R, Lass A (2014) Measurement of lipolysis. Methods Enzymol 538: 171-193

18. Frezza C, Cipolat S, Scorrano L (2007) Organelle isolation: functional mitochondria from mouse liver, muscle and cultured fibroblasts. Nat Protoc 2:287-295

19. Schlager S, Goeritzer M, Jandl K et al (2015) Adipose triglyceride lipase acts on neutrophil lipid droplets to regulate substrate availability for lipid mediator synthesis. J Leukoc Biol 98:837-850

20. Cui Q, Lewis IA, Hegeman AD et al (2008) Metabolite identification via the Madison Metabolomics Consortium Database. Nat Biotechnol 26:162-164

21. Wolfrum C, Stoffel M (2006) Coactivation of Foxa2 through Pgc1 beta promotes liver fatty acid oxidation and triglyceride/VLDL secretion. Cell Metab 3:99-110 
22. Sheena V, Hertz R, Nousbeck J, Berman I, Magenheim J, Bar-Tana J (2005) Transcriptional regulation of human microsomal triglyceride transfer protein by hepatocyte nuclear factor-4alpha. J Lipid Res 46:328-341

23. Knights AJ, Funnell AP, Pearson RC, Crossley M, Bell-Anderson KS (2014) Adipokines and insulin action: a sensitive issue. Adipocyte 3:88-96

24. Sinha MK, Opentanova I, Ohannesian JP et al (1996) Evidence of free and bound leptin in human circulation. Studies in lean and obese subjects and during short-term fasting. J Clin Invest 98:1277-1282

25. Comert B, Mas MR, Erdem $\mathrm{H}$ et al (2001) Insulin resistance in nonalcoholic steatohepatitis. Dig Liver Dis 33:353-358

26. Luyckx FH, Lefebvre PJ, Scheen AJ (2000) Non-alcoholic steatohepatitis: association with obesity and insulin resistance, and influence of weight loss. Diabetes Metab 26:98-106

27. Tankurt E, Biberoglu S, Ellidokuz E et al (1999) Hyperinsulinemia and insulin resistance in non-alcoholic steatohepatitis. J Hepatol 31:963

28. Tiwari S, Siddiqi SA (2012) Intracellular trafficking and secretion of VLDL. Arterioscler Thromb Vasc Biol 32:1079-1086

29. Skop V, Cahova M, Papackova Z et al (2012) Autophagylysosomal pathway is involved in lipid degradation in rat liver. Physiol Res 61:287-297

30. Koo SH, Montminy M (2006) Fatty acids and insulin resistance: a perfect storm. Mol Cell 21:449-450

31. Hayhurst GP, Lee YH, Lambert G, Ward JM, Gonzalez FJ (2001) Hepatocyte nuclear factor 4alpha (nuclear receptor 2A1) is essential for maintenance of hepatic gene expression and lipid homeostasis. Mol Cell Biol 21:1393-1403
32. Haluzik MM, Haluzik M (2006) PPAR-alpha and insulin sensitivity. Physiol Res 55:115-122

33. Linden D, Alsterholm M, Wennbo H, Oscarsson J (2001) PPARalpha deficiency increases secretion and serum levels of apolipoprotein B-containing lipoproteins. J Lipid Res 42:1831-1840

34. Dhe-Paganon S, Duda K, Iwamoto M, Chi YI, Shoelson SE (2002) Crystal structure of the HNF4 alpha ligand binding domain in complex with endogenous fatty acid ligand. J Biol Chem 277:37973-37976

35. Yuan X, Ta TC, Lin M et al (2009) Identification of an endogenous ligand bound to a native orphan nuclear receptor. PLoS One 4:e5609

36. Puigserver P, Rodgers JT (2006) Foxa2, a novel transcriptional regulator of insulin sensitivity. Nat Med 12:38-39

37. Adiels M, Olofsson SO, Taskinen MR, Boren J (2008) Overproduction of very low-density lipoproteins is the hallmark of the dyslipidemia in the metabolic syndrome. Arterioscler Thromb Vasc Biol 28:1225-1236

38. Meshkani R, Adeli K (2009) Hepatic insulin resistance, metabolic syndrome and cardiovascular disease. Clin Biochem 42:1331-1346

39. Krauss RM (2004) Lipids and lipoproteins in patients with type 2 diabetes. Diabetes Care 27:1496-1504

40. Asterholm IW, Halberg N, Scherer PE (2007) Mouse Models of Lipodystrophy Key reagents for the understanding of the metabolic syndrome. Drug Discov Today Dis Models 4:17-24

41. Pilkis SJ, Granner DK (1992) Molecular physiology of the regulation of hepatic gluconeogenesis and glycolysis. Annu Rev Physiol 54:885-909

42. Sundaram M, Yao Z (2010) Recent progress in understanding protein and lipid factors affecting hepatic VLDL assembly and secretion. Nutr Metab (Lond) 7:35 